\title{
Covering Digestive Diseases and Sciences: How to Judge a Journal by Its Cover
}

\author{
Bea M. U. Palileo • Jonathan D. Kaunitz
}

Published online: 16 March 2013

(C) Springer Science+Business Media New York (Outside the USA) 2013

After 79 years of continuous publication, Digestive Diseases and Sciences (DDS) now toasts the fourteenth version of its cover! Here we trace the historical background of DDS through the many iterations of its cover in order to imbue the journal with the degree of authenticity, credibility, and gravitas that it so richly deserves-and that has been attested to in previously published historical accounts $[1,2]$.

\section{The American Journal of Digestive Diseases and Nutrition}

In March 1934, the precursor of DDS was founded with the title-The American Journal of Digestive Diseases and Nutrition (AJDDN) - by Dr. Beamount S. Cornell. Also in 1934, a former president of the American Gastroenterological Association (AGA), Dr. Frank S. Smithies took the challenge of becoming its first editor-in-chief [6692]. The AJDDN was founded with high hopes and much fanfare by

B. M. U. Palileo

College of Letters and Sciences, University of California, Los Angeles, CA, USA

\section{J. D. Kaunitz}

Departments of Medicine and Surgery, School of Medicine, University of California, Los Angeles, CA, USA

\section{J. D. Kaunitz}

Gastrointestinal Service, Greater Los Angeles

Healthcare System, Los Angeles, CA 90073, USA

\section{J. D. Kaunitz ( $\square)$}

West Los Angeles VAMC, 11301 Wilshire Boulevard, Building 114, Room 217E, Los Angeles, CA 90073, USA

e-mail: jonathan.kaunitz@va.gov
Dr. Smithies, stating, "This journal is fortunately favored by the support of a distinguished, respected, and geographically well distributed Editorial Council" [3]. Of note, the Editorial Council of AJDDN consisted of 92 top achievers in the fields of clinical medicine, parisitology, nutrition, roentgenology (as radiology was then called), surgery, experimental physiology, and therapeutics (pharmacology). This list, in retrospect, is all the more impressive since many members were quite junior, at assistant professor and instructor rank, but who became luminaries later in their careers. Notable among these luminaries were: Walter Alvarez, one of the pioneers of modern gastroenterology; Burrill Crohn, who published the seminal description of regional ileitis in 1932; Julius Freidenwald, another GI pioneer and namesake of a prestigious award conferred by the AGA; Sara Jordan, who became the first woman AGA president in 1942 and cofounded of the Lahey Clinic; Leon Schiff, a founder of the field of hepatology and first AASLD president in 1950; Kenneth Merrill Lynch, who modernized the Medical University of South Carolina; Lester Dragstedt, a pioneer and innovator of peptic ulcer surgery; Frank Lahey, cofounder (with Sara Jordan) of the Lahey Clinic; Edward Ochsner, founder of the Ochsner Clinic; Frederick Banting, Nobel laureate for the discovery of insulin; and Andrew Ivy, noted GI physiologist and American Physiological Society president in 1939. The covers of Volume 1 proudly display the title in a beautiful hand-tooled, open-faced font, featuring a detailed table of contents and the name of the first publisher, Sandfield Publishing Co, which was owned by Dr. Cornell. The first issue in March 1934 featured the names of the Editorial Council (Fig. 1a).

Due to the high caliber of its first issues, AJDDN became the official journal of the AGA. necessitating a cover change by the addition of "The Official Publication 


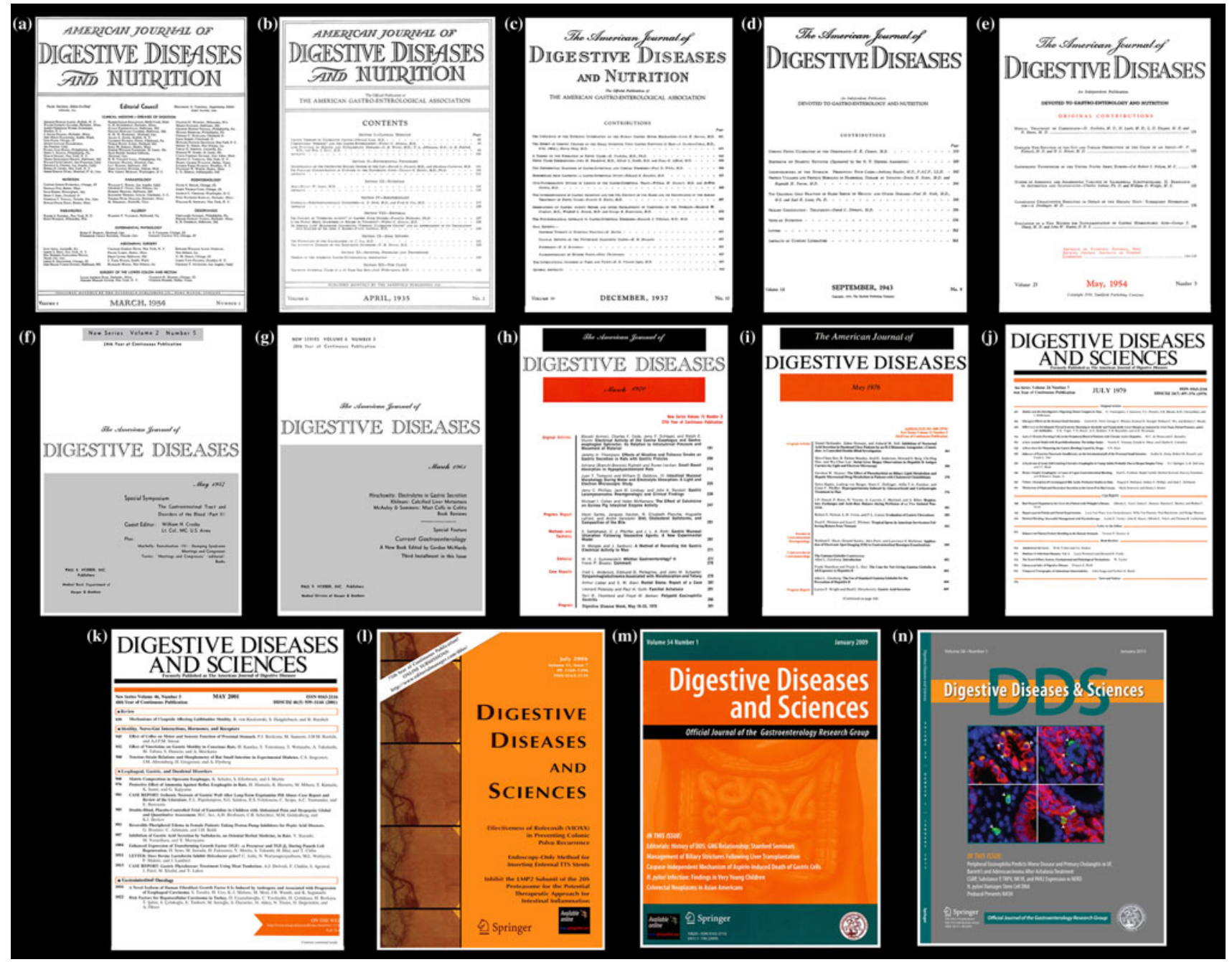

Fig. 179 years of Digestive Diseases covers

of the American Gastroenterological Association" below the masthead (Fig. 1b).

The year 1937 was significant with Dr. Cornell becoming the supervising editor after Dr. Smithies' untimely passing on February 9, 1937. With this change in leadership also came a new cover page for Volume 4 (Fig. 1c). "The American Journal of" was now in script with the font of "Digestive Diseases and Nutrition" retaining an open-faced font that was simpler than its predecessors. This cover, however, lasted for only 1 year (1937-1938), its discontinuation coinciding with Dr. Cornell's sudden resignation from the AGA over its criticism of his article espousing a controversial etiology of GIrelated cancer [6693]. In 1938, Dr. Walter C. Alvarez became the editor-in-chief, and continued in this role until 1942. In 1943, Gastroenterology replaced AJDDN as the official journal of the AGA. In the same year, Dr. Cornell resumed control of AJDDN, with the cover page now sporting a shortened title "The American Journal of
Digestive Diseases" (AJDD) a title which persisted until 1978, and which substituted for the now defunct relationship with the AGA, the attribution "An Independent Publication DEVOTED TO GASTROENTEROLOGY AND NUTRITION" (Fig. 1d).

Between 1943 and 1955, AJDD did not fare well, with declining page counts, advertising, and article quality. Even a change in cover design in 1950, with its red fonts for some entries proved ineffective in reversing the slide (Fig. 1e). This period ended in 1955 when AJDD was sold to publisher, Paul B. Hoeber, Inc., a subsidiary of Harper \& Row and marking the end of the Cornell/Sandfield era.

In January 1956, AJDD was revitalized with new coeditors, Drs. Henry D. Janowitz and Maxwell H. Poppel, and a new editorial board. To signify this fresh start, AJDD was re-launched with volume 1 , number 1 (New Series) accompanied by a new cover design characterized by a two-toned white and gray background but retaining the title typography of its predecessors (Fig. 1f). The title, however, 
was smaller and placed in the middle of the page instead of at the top. From 1956 to 1978 , only small changes were made to the covers (see volume 6 -Fig. $1 \mathrm{~g}$ ) until a totally new look emerged with volume 15 (Fig. 1h). In 1973, the journal was purchased by Plenum at a time when there was large-scale consolidation and restructuring in the publishing industry. This culminated in a merger with Kluwer and the emergence of Springer as current publisher. Although the title typography was preserved, a reddish-orange bar was added to the cover along with new format and fonts for the table of contents. With volume 21 , the open-faced title font was replaced after 42 years in favor of a Roman font that would persist for an additional 30 years (Fig. 1i). As noted in Dr. Keeffe's editorial [1], AJDD had several illustrious editors during that era, including Drs. Henry D. Janowitz, E. Clinton Texter. Jr, and John Farrar.

\section{Digestive Diseases and Sciences}

In 1979 with volume 24, AJDD was renamed DDS 2 years after Dr. Sidney F. Phillips became the editor-in-chief. The cover for the newly-named journal retained much of the look of the AJDD, including its cover fonts and orange and black bars (Fig. 1j). Notably, and as a tip of the hat to its long history, the phrase, "Formerly Published as the American Journal of Digestive Diseases," was printed under the masthead. The new title was chosen to reflect that the journal had become more global in scope and broad based including basic science and clinical articles covering the alimentary tract and liver. Dr. Frank B. Brooks edited DDS from 1982 to 1987 followed by Dr. Richard L. Wechsler from 1988 to 2007. By the end of Dr. Wechsler's term, $67 \%$ of the articles were from outside the US, including China, Japan, India, South Korea and Turkey [1]. During Dr. Wechsler's editorship, there were 3 cover changes, with minor modification starting with volume 40 in 1995 (Fig. 1k) to a more marked change in January 2004 with volume 54 (Fig. 11). This new cover was mostly orange-red, had entirely new typography, and incorporated multiple images along its left border. The reminder about the journal's former title was deleted and its new publisher, Springer featured. The table of contents was substituted with teasers about selected articles published within, although the misspelling of "Internal" certainly raised concern. In 2008, Dr. Emmet B. Keeffe was brought in as editor-in-chief to once again revitalize DDS. The typography was freshened with the colors changed to a brighter orange with muted lower intestinal tract image in the background, introduction of a teal-green color bar, and new fonts (Fig. 1m). A new caption was added: "The Official Journal of the Gastroenterology Research Group," to showcase DDS as the journal's new sponsor.
The most recent change in cover page emerged in January 2013, with the issue displaying an attractive gray, orange, and turquoise theme and featuring striking images from articles published in the issue (Fig. 1n). The change in cover also included a prominent, larger font for the acronym, all changes designed to make DDS more visually appealing and marking the transition from print to online delivery (Table 1).

DDS and the evolution of its cover pages represent a microcosm of the history of gastroenterology. At 79 years of age with this issue, it is a venerable journal, though not the oldest in the field with Archiv für Verdauungskrankheiten, the forerunner of today's Digestion, dating back to 1895, and The Review of Gastroenterology, forerunner of American Journal of Gastroenterology, initially published in March 1934, a dead heat with AJDDN [4]. Although increasing specialization would make impossible to publish a journal so all-encompassing as the original AJDDN, the fundamental principles, as stated by Dr. Smithies, still holds for its legacy as DDS that “.... a serious and persistent effort will be made to establish and maintain this publication in an authoritative position...[through]...regular publication of judiciously selected contributions from wellknown clinicians and investigators..." Indeed, the changing covers of what is now DDS not only reflect the history of gastroenterology, but a statement of its evolution into a science-based, highly technical discipline Given the support of its publisher, strength of its foundation and support of the GRG, DDS is now exceptionally wellpositioned for growth and expansion-and in that promise,

Table 1 The fourteen cover types for AJDDN/AJDD/DDS

\begin{tabular}{|c|c|c|}
\hline Figure no. & Volume number(s) & Dates \\
\hline \multicolumn{3}{|c|}{ The American Journal of Digestive Diseases and Nutrition } \\
\hline $1 \mathrm{a}$ & Vol 1 & March 1934-February 1935 \\
\hline $1 b$ & Vol 2-Vol 3 & March 1935-February 1937 \\
\hline $1 \mathrm{c}$ & Vol 4 & March 1937-February 1938 \\
\hline $1 d$ & Vol 5-Vol 16 & March 1938-December 1949 \\
\hline $1 \mathrm{e}$ & Vol 17-Vol 22 & January 1950-December 1955 \\
\hline \multicolumn{3}{|c|}{ The American Journal of Digestive Diseases (new series) } \\
\hline 1f & Vol 1-Vol 5 & January 1956-December 1960 \\
\hline $1 \mathrm{~g}$ & Vol 6-Vol 14 & January 1961-December 1969 \\
\hline $1 \mathrm{~h}$ & Vol $15-$ Vol 20 & January 1970-December 1975 \\
\hline $1 \mathrm{i}$ & Vol 21-Vol 23 & January 1976-December 1978 \\
\hline \multicolumn{3}{|c|}{ Digestive Diseases and Sciences } \\
\hline $1 \mathrm{j}$ & Vol 24-Vol 39 & January 1979-December 1994 \\
\hline $1 \mathrm{k}$ & Vol 40-Vol 48 & January 1995-December 2003 \\
\hline 11 & Vol 49-Vol 53 & January 2004-December 2008 \\
\hline $1 \mathrm{~m}$ & Vol 54-Vol 57 & January 2009-December 2012 \\
\hline $\ln$ & Vol 58-Present & January 2013-Present \\
\hline
\end{tabular}


can you begin to see just over the horizon, yet another cover change!

\section{References}

1. Keeffe EB. Digestive Diseases and Sciences-past, present, and future. Dig Dis Sci. 2009;54:1-4.
2. Farrar JT. The American Journal of Digestive Diseases, 1934-1977. Dig Dis Sci. 1979;24:1-3.

3. Smithies F. Foreword. Am J Dig Dis. 1934;1:72.

4. Brandt LJ. Ismar Boas: father of gastroenterology and founder of the oldest surviving publication in digestive diseases. Am $J$ Gastroenterol. 2011;106:171-172. 